\title{
Outcome of operative intervention in intramedullary spinal cord tumours
}

\author{
Manish Jaiswal, Radhey Shyam Mittal \\ Department of neurosurgery, SMS Medical College and Hospital, JLN Marg, Jaipur (302004), \\ Rajasthan, India
}

\begin{abstract}
Objective: The authors analysed the outcome of intramedullary spinal cord tumour surgery, focusing on the preoperative \& postoperative neurological status and influence of preoperative gait status on postoperative gait.

Methods: Retrospective analysis of medical records of 53 intramedullary tumour patients, operated at our institute between Jan 2006 and July 2012 was done. Pre - and postoperative neurological status was determined. Preoperative MRI was done. Ambulatory status were evaluated using the modified McCormick Scale. All the patients were operated using standard microsurgical techniques. Extent of resection was quantified by direct visualization with microscope as: gross resection, subtotal resection, partial resection, and biopsy.

Results: $73.5 \%$ of the patients were in $40-60$ years of age group (age range, 5-81 years; mean age 41 years). Region most commonly affected was thoracic (40\%). The preoperative McCormick grade was I in 20 (37.7\%), II in 16 (30.1\%), III in 7 (13.2\%), IV in 9 (16.9\%), and $\mathrm{V}$ in $1(1.88 \%)$ patients. Gross resection was
\end{abstract}

possible in $54.7 \%$ of cases. Gross resection rate was significantly higher in good preoperative gait (grade - I). Histologically $41.5 \%$ of the lesions were ependymomas. Overall postoperative neurological status improved in $16(30.3 \%)$ of the patients, remained unchanged in $27(50.9 \%)$ of cases, and deteriorated in $10(18.8 \%)$ patients.

Conclusions: Better final outcome of walking ability correlated with good preoperative gait. Higher Gross resection rate was found in cases at an early stage. We favor early and optimal resection of tumour to give least morbidity and better quality of life.

Key words: Intramedullary spinal cord tumour; Intramedullary tumour outcome; Spinal tumour

\section{Introduction}

Intramedullary spinal cord tumors (IMSCT) are relatively rare tumors, accounting for only $2 \%$ to $4 \%$ of central nervous system tumors. In adults IMSCT comprise $20 \%$ of all intraspinal spinal tumours while in children $35 \%$ of tumours are IMSCT [1]. The various cell types within the spinal cord are responsible for the similar variety of 
histological subtypes of intramedullary tumors. Astrocytes, oligodendrocytes, neurons, ependymal lining and blood vessels may all give rise to intramedullary tumors. The most frequent of these tumors are of glial origin, astrocytomas and ependymomas comprising the majority of them. Unlike brain tumors, most cases, with a few exceptions, are pathologically benign. The clinical course of these tumors is most often an insidious process. By the time evident neurological signs are present, neurological compromise is irreversible and these tumors have often grown to an extent that makes surgical resection morbid or impossible [2].

The management of IMSCT remained controversial in the past, when these were often treated with biopsy or subtotal removal followed by radiotherapy but this therapy mode was usually associated with early tumour recurrence and progressive neurological deterioration [3]. With advent and later improvement of microsurgical procedures, complete or near total resection of IMSCT is possible with much better outcome and very less chances of recurrence and late neurological deterioration [4].

In this study, we analysed the outcomes of IMSCT surgery, focusing on the preoperative \& postoperative neurological status in (IMSCT) and influence of preoperative gait status on postoperative gait.

\section{Material and methods}

We retrospective analyzed medical records of 53 patients ( 30 males and 23 females) who were operated at our institute between Jan 2006 and July 2012 and were histopathologically proven IMSCT. Patients who lost follow-up before 6months and had not exact medical records or pathological reports were excluded from analysis. Pathological reports were obtained from postoperative specimens for all patients. Preand postoperative neurological status was determined from their hospital records. Preoperative diagnosis was made by Gadolinium-enhanced MRI. Ambulatory status were evaluated using the modified McCormick Scale, [Grade I = normal gait, Grade II = mild gait disturbance not requiring support, Grade III= gait with support, Grade $\mathrm{IV}=$ assistance required, Grade $\mathrm{V}=$ wheel chair/ bed ridden].

All the patients were operated using standard microsurgical techniques. Extent of resection was quantified by direct visualization with microscope by operating neurosurgeons as total resection: removal of $100 \%$ of the tumour as evidenced by a microscopically documented clean surgical field at the end of the procedure. When a small tumour fragment was deliberately left in place, the procedure was considered to be a subtotal resection (removal of $80-99 \%$ of tumour). In the same manner, we defined $50-80 \%$ resection as partial resection and $<50 \%$ resection was defined as a biopsy. Confirmation of the extent of resection was done by Gd-MRI one month postoperatively. Data was analyzed using SPSS-15.

\section{Results}

In this study most of the patients (73.5\%) were in 40-60 years of age group of life (age range, 5-81 years; mean age 41 years). 
DOI: 10.2478/romneu-2014-0038

Distribution of tumour according to age is shown in (Figure 1). Most common preoperative symptoms or first clinical findings were: paraparesis in 31 (58.4\%) cases, bladder bowel symptoms in 28 (52.\%) cases, pain in $26(49 \%)$ cases, numbness and quadriparesis each in 17 (32\%) cases, brown sequard syndrome in $2(3.7 \%)$ cases, and paraplegia in $1(1.89 \%)$ case. Our result demonstrates the most frequent tumour was ependymoma 22/53 (41.5\%) and followed by astrocytoma 16/53 (30.1\%) (Table 1$)$.

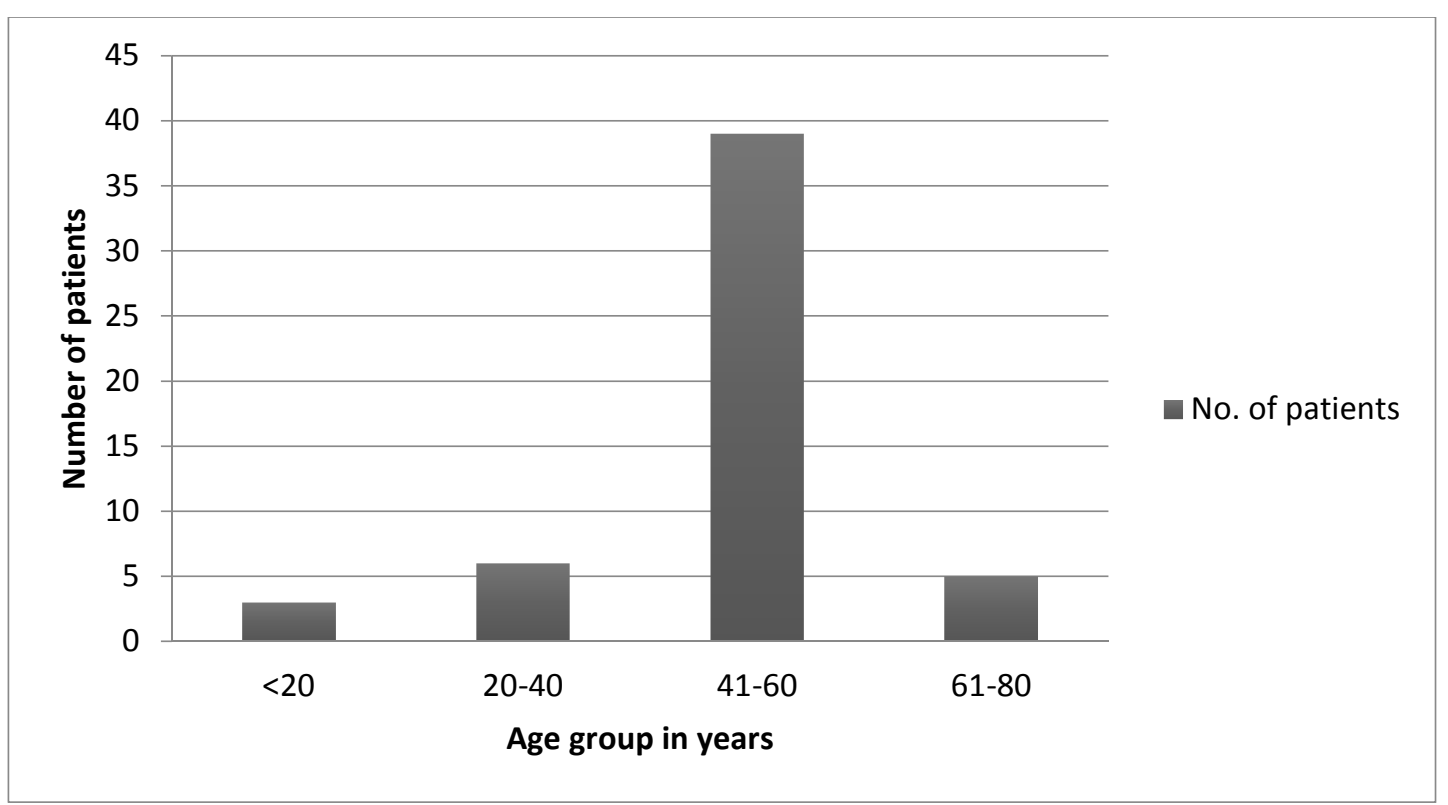

Figure 1 - Age group distribution of intramedullary spinal cord tumour

\section{TABLE 1}

Histopathological subtypes of intramedullary spinal cord tumours

\begin{tabular}{|lll|}
\hline Histological subtypes & Number & $\%$ of total \\
\hline Ependymoma & 22 & $41.5 \%$ \\
\hline Astrocytoma & 16 & $30.1 \%$ \\
\hline Anaplastic astrocytoma & 06 & $11.4 \%$ \\
\hline Hemangioblastoma & 04 & $7.5 \%$ \\
\hline Ganglioglioma & 02 & $3.8 \%$ \\
\hline Teratoma & 01 & $1.89 \%$ \\
\hline Lipoma & 01 & $1.89 \%$ \\
\hline Epidermoid & 01 & $1.89 \%$ \\
\hline
\end{tabular}


Region most commonly affected was thoracic (40\%) followed by conus medullaris (30\%), number and location of tumour showed in (Table 2).

The preoperative McCormick grade was I in 20 (37.7\%), II in 16 (30.1\%), III in 7 (13.2\%), IV in $9(16.9 \%)$, and $\mathrm{V}$ in $1(1.88 \%)$ patients. Neurological status was aggravated after surgery (assessed at the time of discharge) in 20 (37.7\%) of the 53 patients. In patients who could not walk after surgery and whose McCormick scale grade was IV or V, the preoperative score was I in 2 patients (10\%), II in 4 (25\%), III in 1 (14.2\%), and IV and V in 6 (60\%). Gait disturbance was almost absent after surgery-Grade I or II in 16 (80\%) of the 20 cases with grade I status before surgery, 9 (56.2\%) of the 16 with preoperative grade II, $4(57.1 \%)$ of the 7 with preoperative grade III, $1(11.1 \%)$ of the 9 with preoperative grade IV, and none of the 1 with preoperative grade V. on statistical analysis, postoperative gait was significantly better when the preoperative McCormick scale was I-III ( $\mathrm{p}<0.001)$ (Table 3).
At 6 months after surgery, 19 (95\%) of the 20 preoperative grade I cases, $12(75 \%)$ of the 16 preoperative grade II cases, $5(71.4 \%)$ of the 7 preoperative grade III cases, $2(20 \%)$ of the 10 preoperative grade IV and $\mathrm{V}$ cases had almost no gait disturbance (Grade I-III), indicating that, when the preoperative grade was I-III, the gait was favorable immediately to 6 months after surgery and the gait was improved at 6 months, compared with that at the time of discharge after surgery (Table 4).

Regarding the relationship between the amount of tumour resection and preoperative neurological manifestation, gross resection was performed in 15 (75\%) of the 20 patients with preoperative grade I status, $6(37.5 \%)$ of the 16 with preoperative grade II status, 3 (42.8\%) of the 7 patients with preoperative grade III status, $5(50 \%)$ of the 10 patients with preoperative grade IV and V status, demonstrating that the total resection rate was significantly higher in patients with good preoperative gait (Grade I) $(\mathrm{p}<0.001)$ (Table 5).

TABLE 2

Intramedullary spinal cord tumour (IMSCT) location distribution

\begin{tabular}{|lll|}
\hline Location & Number & Percentage \\
\hline Cervical & 10 & $19 \%$ \\
\hline Cervico-thoracic & 06 & $11 \%$ \\
\hline Thoracic & 21 & $40 \%$ \\
\hline Conus & 16 & $30 \%$ \\
\hline
\end{tabular}


TABLE 3

Summary of comparison between preoperative and postoperative McCormick grades at the time of discharge of patients

\begin{tabular}{|lllllll|}
\hline $\begin{array}{l}\text { Pre-op } \\
\text { Grade }\end{array}$ & $\begin{array}{l}\text { Postop. } \\
\text { McCormick } \\
\text { Grade I }\end{array}$ & $\begin{array}{l}\text { Postop. } \\
\text { McCormick } \\
\text { Grade II }\end{array}$ & $\begin{array}{l}\text { Postop. } \\
\text { McCormick } \\
\text { Grade III }\end{array}$ & $\begin{array}{l}\text { Postop. } \\
\text { McCormick } \\
\text { Grade IV }\end{array}$ & $\begin{array}{l}\text { Postop. } \\
\text { McCormick } \\
\text { Grade V }\end{array}$ & Total \\
\hline I & 11 & 05 & 02 & 01 & 01 & 20 \\
\hline II & 03 & 06 & 03 & 02 & 02 & 16 \\
\hline III & 01 & 03 & 02 & 00 & 01 & 07 \\
\hline IV & 00 & 01 & 03 & 02 & 03 & 09 \\
\hline V & 00 & 00 & 00 & 00 & 01 & 01 \\
\hline Total & 15 & 15 & 10 & 05 & 08 & 53 \\
\hline
\end{tabular}

\section{TABLE 4}

Summary of comparison between preoperative and postoperative McCormick grades at 6 months follow-up of patients

\begin{tabular}{|c|c|c|c|c|c|c|}
\hline Preop. & Postop. & Postop. & Postop. & Postop. & Postop. & Total \\
\hline \multirow[t]{2}{*}{ Grade } & McCormick & McCormick & McCormick & McCormick & McCormick & \\
\hline & Grade I & Grade II & Grade III & Grade IV & Grade V & \\
\hline I & 15 & 04 & 01 & 00 & 00 & 20 \\
\hline II & 06 & 06 & 02 & 01 & 01 & 16 \\
\hline III & 02 & 03 & 02 & 00 & 00 & 07 \\
\hline IV & 00 & 02 & 03 & 03 & 01 & 09 \\
\hline $\mathbf{V}$ & 00 & 00 & 00 & 00 & 01 & 01 \\
\hline Total & 23 & 15 & 08 & 04 & 03 & 53 \\
\hline
\end{tabular}

\section{TABLE 5}

Correlation of McCormick grade and extent of tumour resection in overall population of 53 patients with IMSCTs

\begin{tabular}{|llllll|}
\hline $\begin{array}{l}\text { Preop } \\
\text { McCormick } \\
\text { grade }\end{array}$ & $\begin{array}{l}\text { Gross resection } \\
(\%)\end{array}$ & $\begin{array}{l}\text { Subtotal } \\
\text { resection }\end{array}$ & $\begin{array}{l}\text { Partial } \\
\text { resection }\end{array}$ & biopsy & $\begin{array}{l}\text { Total no. of cases } \\
(\%)\end{array}$ \\
\hline I & $15(75 \%)$ & 02 & 02 & 01 & $20(37.7 \%)$ \\
\hline
\end{tabular}




\begin{tabular}{|llllll|}
\hline II & $06(37.5 \%)$ & 03 & 05 & 02 & $16(30.1 \%)$ \\
\hline III & $03(42.8 \%)$ & 01 & 02 & 01 & $07(13.2 \%)$ \\
\hline IV & $05(55.5 \%)$ & 00 & 02 & 02 & $09(16.9 \%)$ \\
\hline V & $00(0 \%)$ & 00 & 01 & 00 & $01(1.88 \%)$ \\
\hline Total & $29(54.7 \%)$ & $06(11.3 \%)$ & $12(22.6 \%)$ & $06(11.3 \%)$ & 53 \\
\hline
\end{tabular}

\section{Discussion}

First ever successful resection of an IMSCT was performed by Anton Von Eiselsberg in 1907, but the first report about such resection appeared in 1911 by Charles Elsberg in New York who explained two-staged plan for surgery for the removal of these IMSCTs [5]. Only a few surgeons initially reported good outcomes [6]. Several treatment protocols involving biopsies, decompressive laminectomies and adjuvant treatments such as radiation therapy became the norm up to as far as the 1960s [6] Greenwood was one of these pioneering neurosurgeons and since his 1954 paper was an advocate of total resection of these tumors [7]. He was later joined by other accomplished surgeons such as Yasargil, Malis, Stein and De Sousa $[8,9,10]$. Even though they had shown improved results with the help of the surgical microscope and bipolar coagulation, diagnosis was frequently established late in the clinical course of this condition, a situation that would only improve in the mid-1980s with the advent of magnetic resonance imaging (MRI), improvement of microsurgical procedures. The widespread usage of CUSA in intramedullary spinal cord tumour resection, and the usage of intraoperative neurophysiological monitoring have caused an increase in total resection rate to $90 \%$ and led to a significant change in the approach to IMSCTs $[11,12,13,14,15]$. According to many authors, the aim of IMSCTs surgery is optimal resection and protection of neurological function $[11,16,17$, $18,19,20,21,22]$.

We followed 53 surgically treated patients with IMSCTs, investigated the outcomes, particularly the post- operative gait in relation to the various preoperative gait states, and identified the extent of tumor excision. In 1999 Kane et al. [24] reported that the gait status was aggravated and unchanged in $6(12 \%)$ and $45(82 \%)$ of 54 patients with intramedullary tumors. In 1994 Cristante and Herrmann [25] reported that the outcome was aggravated, unchanged, and improved in 31,55 , and $17 \%$ of 69 intramedullary tumour cases, respectively. Constantini et al.[1] reported the outcomes of aggravated, unchanged, and improved in $23.8,60.4$, and $15.8 \%$ of 164 cases of pediatric intramedullary tumor, respectively, and Sandalcioglu et al.[14] reported that the outcome was aggravated in $27(34.6 \%)$ and unchanged in $51(65 \%)$ of 78 cases of intramedullary tumor. In our present series the outcome was aggravated, unchanged, and improved in 18.8, 50.9 and $30.3 \%$ of 53 intramedullary tumour cases respectively. Despite advances in the surgical procedure, gait status became aggravated 
DOI: 10.2478/romneu-2014-0038

following surgery for intramedullary tumor in 20-30\%.

Immediate postoperative neurological deterioration was observed in 20 (37.7\%) cases, no change in $22(41.5 \%)$ cases and improvement in 11(20.7\%) cases of our total 53 patients, but those patients who seek treatment early in their clinical course frequently reach their preoperative activity level or even improve beyond that (worsen patients number was reduced from 20 to 10 , no change and improved status patients number increased from 22 to 27 and 11 to 16 respectively at 6 months follow-up), so in cases of IMSCTs one should not wait for the onset of clinical deterioration but rather institute treatment as soon as possible. The earlier the diagnosis and the more radical the resection of an IMSCT, the greater the likelihood of preserving the patient's neurological function [26]. It has been reported that gross total resection is usually sufficient to achieve recovery of the lesions or the long-term control of the tumour $[2,9,12,17]$. As a result of a long-term followup study of 202 cases, Raco et al.[22] reported that the surgical goal should be the removal of the entire spinal cord tumour. For malignant tumors, the primary objective was to achieve favorable postoperative gait as much as possible, not relying completely on total resection, but for benign tumors (ependymoma, hemangioma, and hemangioblastoma), total resection is desirable and should be attempted $[1,17,27,5$, 26]. Maintaining total resection may aggravate postoperative neurological manifestations, leading to poor gait (McCormick Scale Grades
III, IV, and V), which markedly affects the quality of life of the patient.

No adjuvant treatments (including radiotherapy) were used in the postoperative period in our cases. The dominant opinion in the literature is that the standard treatment for is radical resection, and that radiation therapy after gross total resection is unnecessary $[3,17$, 20]. However, when there is a possibility of residual tumours or a diagnosis of malignant pathology, postoperative radiotherapy is recommended [23].

In this series, no neurophysiological monitoring were available and we do not have any experience with intraoperative neurophysiological monitoring. Some surgeons have shown these instruments to be helpful but not indispensable for a successful outcome. Raco et al. [22] observed that intraoperative neurophysiological monitoring is not helpful for determining postoperative motor and sensory deficits.

No doubt there are some limitations in our study. Our study is retrospective, single institutional study and having large descriptive data. Statistical analysis could not be performed between certain groups like tumour type and age group due to small number of patients. Intra-operative USG and spinal cord monitoring facilities are not available at our institute, which limit extent of resection in our series and certainly there is room for improvement.

\section{Conclusion}

Better final outcome of walking ability correlated with good preoperative gait. Higher Gross resection rate was found in cases at an 
early stage of preoperative McCormick grade. The postoperative gait was less aggravated in good preoperative McCormick grade cases. All of these inferences favour early and optimal resection to give least morbidity and better quality of life to IMSCT patients.

\section{Correspondence}

Dr. Manish Jaiswal

A 33/48 A 2, Omkareshwar

Varanasi, 221001, Uttar Pradesh, India

Phone - 091-9799980494

E-mail-manishmlnmc@gmail.com

\section{References}

1.Constantini S, Miller DC, Allen JC, Rorke LB, Freed D, Epstein FJ. Radical excision of intramedullary spinal cord tumours: surgical morbidity and long-term follow-up evaluation in 164 children and young adults. J Neurosurg 2000;93(2 Suppl):183-93.

2.Jellema K, Overbeeke JJ, Teepen HLJM. Time to diagnosis of intraspinal tumors. Eur J Neurol 2005;12:621-624.

3.Cooper PR, Epstein F. Radical resection of intramedullary spinal cord tumours in adults. Recent experience in 29 patients. J Neurosurg 1985;63:492-9.

4.Ohata K, Takami T, Gotou T, El-Bahy K, Morino M, Maeda M, et al. Surgical outcome of intramedullary spinal cord ependymoma. Acta Neurochir (Wien) 1999;141:341-6.

5.Sala F, Bricolo A, Faccioli F, Lanteri P, Gerosa M. Surgery for intramedullary spinal cord tumours: the role of intraoperative neurophysiological) monitoring. Eur Spine J 2007;16(Suppl 2):S130-9.

6.Poppen JL. An atlas of neurosurgical techniques. Philadelphia \& London: W.B. Saunders \& Co 1960:424428.

7.Greenwood Jr J. Total removal of intramedullary tumors. J Neurosurg 1954;11:616-621.

8.Chi JH, Cachola K, Parsa AT. Genetics and molecular biology of intra-medullary spinal cord tumors. Neurosurg Clin N Am 2006;17:1-5.

9. Malis LI. Intramedullary spinal cord tumors. Clin Neurosurg 1978;25: 512-539.
10.Stein BM. Surgery of intramedullary spinal cord tumors. Clin Neuro-surg 1979;26:529-542.

11.Aghakhani N, David P, Parker F, Lacroix C, Benoudiba F, Tadie M: Intramedullary spinal ependymomas: analysis of a consecutive series of 82 adult cases with particular attention to patients with no preoperative neurological deficit. Neurosurgery 62: 1279-1285; discussion 1285-1286, 2008

12.Hanbali F, Fourney DR, Marmor E, Suki D, Rhines LD, Weinberg JS, et al.: Spinal cord ependymoma: radical surgical resection and outcome. Neurosurgery 51: 11621172; discussion 1172-1174, 2002

13.Nakamura $\mathrm{M}$, Ishii $\mathrm{K}$, Watanabe $\mathrm{K}$, Tsuji $\mathrm{T}$, Takaishi $\mathrm{H}$, Matsumoto $\mathrm{M}$, et al.: Surgical Treatment of intramedullary spinal cord tumours: prognosis and complications. Spinal Cord 46: 282-286, 2008

14.Sandalcioglu IE, Gasser T, Asgari S, Lazorisak A, Engelhorn T, Egelhof T, et al.: Functional outcome after surgical treatment of intramedullary spinal cord tumours: experience with 78 patients. Spinal Cord 43: 34-41, 2005 15.Sun B, Wang C, Wang J, Liu A: MRI features of intramedullary spinal cord ependymomas. J Neuroimaging 13: 346-351, 2003

16.Chang UK, Choe WJ, Chung SK, Chung CK, Kim HJ: Surgical outcome and prognostic factors of spinal intramedullary ependymomas in adults. J Neurooncol 57: 133-139, 2002

17.Epstain FJ, Farmer JP, Freed D: Adult intramedullary spinal cord ependymomas: the result of surgery in 38 patients. J Neurosurg 79: 204-209, 1993

18.Lin YH, Huang CI, Wong TT, Chen MH, Shiau CY, Wang LW, et al.: Treatment of spinal cord ependymomas by surgery with or without postoperative radiotherapy. J Neurooncol 71: 205-210, 2005

19.McCormick PC, Stein BM: Intramedullary tumours in adults. Neurosurg Clin N Am 1: 609-630, 1990 20. McCormick PC, Torres R, Post KD, Stein BM: Intramedullary ependymoma of the spinal cord. J Neurosurg 72: 523-532, 1990

21.Nakamura M, Ishii K, Watanabe K, Tsuji T, Takaishi $\mathrm{H}$, Matsumoto $\mathrm{M}$, et al.: Surgical Treatment of intramedullary spinal cord tumours: prognosis and complications. Spinal Cord 46: 282-286, 2008

22. Raco A, Esposito V, Lenzi J, Piccirilli M, Delfini R, Cantore G: Long-term follow-up of intramedullary spinal cord tumors: a series of 202 cases. Neurosurgery 56: 972981; discussion 972-981, 2005 
DOI: 10.2478/romneu-2014-0038

23. Shaw EG, Evans RG, Scheithauer BW, Ilstrup DM, Earle JD: Postoperative radiotherapy of intracranial ependymoma in pediatric and adult patients. Int J Radiat Oncol Biol Phys 13: 1457-1462, 1987

24. Kane PJ, el-Mahdy W, Singh A, Powell MP, Crockard HA: Spinal intradural tumors: Part II-Intramedullary. Br J Neurosurg 13:558-563, 1999

25. Cristante L, Herrmann HD: Surgical management of intramedullary spinal cord tumors: functional outcome and sources of morbidity. Neurosurgery 35:69-76, 1994 26. Shrivastava RK, Epstein FJ, Perin NI, Post KD, Jallo GI: Intramedullar spinal cord tumor in patients older than 50 years of age: management and outcome analysis. J Neurosurg Spine 2:249-255, 2005

27. Kothbauer KF: Intraoperative neurophysiological monitoring for intramedullary spinal cord tumor surgery. Neurophysiol Clin 37:407-414, 2007 